\title{
Potentiometric and Spectroscopic Studies of Sulfonamide Azo-Dye Complexes with some Transition Metal Ions and Uranium
}

\author{
E.H. El-Mossalamy* \\ Chemistry Department, Faculty of Science, King Abdul Aziz University, \\ Jeddah-Saudi Arabia
}

\begin{abstract}
Molecular structure of the azo-dye derived from sulfonamide was synthesized. The elucidation of ligand and complex structures were studied by electronic, infrared and $1 \mathrm{H}$ NMR spectroscopies. Proton-ligand constants of sulphonamid azo-derivatives and the stability constant of Mo (III), VO (II), $\mathrm{UO}_{2}$ (II) and Co (II) metal ions with sulfonamide azodye derivatives have been determined potentiometrically in $0.1 \mathrm{M} \mathrm{KCl}$ and $30 \%$ (v/v) ethanol-water mixture. The data are discussed in terms of the electronic character of the substituents and of the change in temperature. The $\mathrm{pK}^{1-\mathrm{H}}$ values have been found to increase with increasing electron donating nature of the subsituents. The evaluated dissociation processes are non spontaneous, endothermic and entropically unfavourable. The order of the stability constants of the formed complexes was found to be $\mathrm{Mo}^{3+}>$ $\mathrm{VO}^{2+}>\mathrm{UO}_{2}{ }^{2+}>\mathrm{Co}^{2+}$. The influence of substituents on the stability of the complexes was examined on the basis of an electron repelling property of the substituent. The effect of temperature on the stability of the formed complexes was studied and the corresponding thermodynamic parameters $(\Delta \mathrm{G}, \Delta \mathrm{H}$ and $\Delta \mathrm{S})$ were evaluated and discussed. The stoichiometries of these complexes were determined conductometrically and indicated the formation of 1:1 and 1:2 (metal:ligand) complexes.
\end{abstract}

Keywords: sulfonamide azo-dyes, potentiometric, conductometic, complexation and thermodynamics.

\footnotetext{
*Corresponding author. E-mail address: mina_elmosalamy96@hotmail.com Permanent address: Chemistry Department, Faculty of Science, Benha University, Benha, Egypt
} 


\section{Introduction}

Azo compounds of rhodanine were synthesized as potential medicinal preparations [1]. Their qualitative reactions with some elements were also reported [2,3]. Sulfonamides were the first effective chemotherapeutic agents to be employed systematically for the prevention and cure of bacterial infections [4]. Although potentiometric studies of azo compounds have been studied extensively, little attention including azo compounds formed by interaction of sulfomamide drugs as ligands has been reported. The influences of the substituents on the proton affinity of the compounds were examined on the basis of inductive effects. The corresponding thermodynamic parameters are derived and discussed.

Ionization potential and substituent effects on the stability constants were also investigated. Furthermore, the corresponding thermodynamic functions of complexation were evaluated and discussed. Moreover, the stoichiometries of these complexes were determined conductometrically at $298 \mathrm{~K}$.

\section{Experimental}

\section{Preparation of the azo compounds}

The sulfonamide azodyes (I-III) were prepared [5] by the gradual addition of an aqueous solution of 0.01 mol of $\mathrm{NaNO}_{2}$ to a conc. $\mathrm{HCl} 1: 1$ solution of 0.01 mole of $\mathrm{N}$ sulfonamide with stirring and kept for about $20 \mathrm{~min}$ in an ice bath at $-10{ }^{\circ} \mathrm{C}$. The formed diazonium chloride solutions were added gradually with vigrous stirring to 0.01 mole cold solutions of phenol(I), p-N(CH$)_{2}$ (II) and p- $\mathrm{NO}_{2}$ (III) derivatives of phenol, respectively. After dilution the compounds (I-III) formed were filtered off and washed with water, the curde materials were recrystallized from ethanol and then dried in a vacuum desiccator over anhydrous calcium chloride. The purity was checked by elemental analysis, IR, melting point and ${ }^{1} \mathrm{H}$ NMR spectra; the compounds have the general structural formula

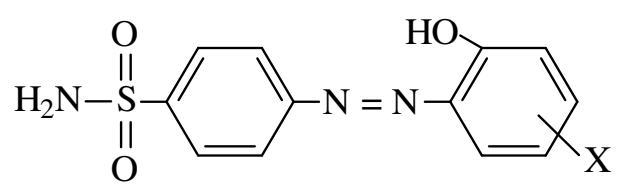

where: $\mathrm{X}=\mathrm{H} \rightarrow(\mathrm{I}) ; \mathrm{p}-\mathrm{N}\left(\mathrm{CH}_{3}\right)_{2} \rightarrow(\mathrm{II})$; and $\mathrm{p}-\mathrm{NO}_{2} \rightarrow$ (III).

\section{Potentiometric measurements}

The apparatus, general conditions and methods of calculation were the same as in previous works [6,7]. The following mixtures were prepared and titrated potentiometrically at $298 \mathrm{~K}$ against standard $0.02 \mathrm{M} \mathrm{NaOH}$ in $30 \%$ (v/v) ethanolwater mixture:

(i) $5 \mathrm{~mL} 0.005 \mathrm{M} \mathrm{HCl}+5 \mathrm{~mL} 1 \mathrm{M} \mathrm{KCl}+15 \mathrm{~mL}$ ethanol;

(ii) $5 \mathrm{~mL} 0.005 \mathrm{M} \mathrm{HCl}+5 \mathrm{~mL} 1 \mathrm{M} \mathrm{KCl}+10 \mathrm{~mL}$ ethanol $+5 \mathrm{~mL} 0.01 \mathrm{M}$ ligand. 
For each mixture, the volume was made up to $50 \mathrm{~mL}$ with doubly distilled water before the titration. These titrations were repeated at temperatures of 308 and 318 K. A constant temperature was maintained to $\pm 0.05 \mathrm{~K}$ by using an ultrathermostat (Neslab 2 RTE 220). The pH-meter readings in $30 \%(\mathrm{v} / \mathrm{v})$ ethanol-water mixture are corrected according to the Van Uitert and Hass relation [8].

\section{Preparation of metal ion complex}

The complexes were prepared by refluxing sulfonamidazo derivatives in ethyl alcohol as solvent. Metal chloride solution complexes were prepared by dissolving equimolecular amounts of ligand and metal chloride in ethyl alcohol. The mixtures were refluxed for $10 \mathrm{hr}$. The complexes were precipitated, filtrated and washed with a large excess of distilled water to remove the metal chloride incorporated in the complexes.

\section{Characterization of ligands-metal chloride complexes}

IR spectra were recorded by means of a Perkin-Elmer Model 683 spectrometer. Samples were examined as $\mathrm{KBr}$ discs. For UV-vis spectroscopy the samples were investigated as a Nujol mull and the spectra recorded with a Perkin-Elmer $\lambda$ 3B spectrophotometer. ESR spectra were recorded on a Varian E-g-Xspectrometer equipped with an E 101 microwave bridge.

\section{Results and discussion}

\section{Proton-ligand stability constants}

The average number of protons associated with the ligands (I-III) at different $\mathrm{pH}$ values, $\mathrm{n}_{\mathrm{A}}$, was calculated from the titration curves of the acid in the absence and presence of the ligand. Thus, the formation curves $\left(\mathrm{n}_{\mathrm{A}} \mathrm{vs} . \mathrm{pH}\right)$ for the protonligand systems were constructed and found to extend between 0 and 2 in the $n_{A}$ scale. This means that ligands have two dissociable protons (the enolized hydrogen ions of the hydroxyl group of the phenyl moiety). It can be seen that for the same volume of $\mathrm{NaOH}$ added the ligand titration curves had a lower $\mathrm{pH}$ value than the free acid titration curve. The displacement of a ligand titration curve along the volume axis with respect to the free acid titration curve is an indication of proton dissociation. The proton-ligand stability constants were calculated using the method of Irving and Rossotti [9].

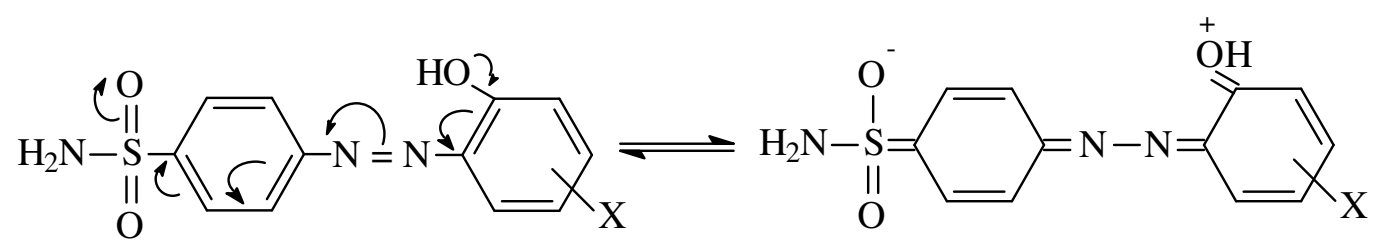

The phenolic-OH group is known to be weakly acidic, indicating a stronger bonding between the proton and the oxygen atom. This means that the protonligand stability constant of sulfonamide moiety $\left(\mathrm{pK}_{2}{ }^{\mathrm{H}}\right)$ should be higher than the phenolic group $\left(\mathrm{pK}_{1}{ }^{\mathrm{H}}\right)$, due to the dissociation of - $\mathrm{OH}$ group 


\section{Substituent effect on $\mathrm{PK}^{\boldsymbol{H}}$}

An inspection of the results in Table 1 reveals that the $\mathrm{PK}_{1}{ }^{\mathrm{H}}$ values of the compounds are influenced by the inductive effect of the substituents. The presence of $-\mathrm{N}\left(\mathrm{CH}_{3}\right)_{2}$ group (i.e. an electron donating effect) will enhance the electron density by their high positive inductive effect, whereby stronger $\mathrm{O}-\mathrm{H}$ bond in sulfonamide group is found leading to a higher $\mathrm{PK}_{1}{ }^{\mathrm{H}}$ value.

Table 1. Stepwise stability constants for the complexation of substituted sulfonamide azo-dyes with $\mathrm{Mo}^{3+}, \mathrm{UO}_{2}{ }^{2+}, \mathrm{VO}^{2+}$, and $\mathrm{Co}^{2+}$ in $20 \%(\mathrm{v} / \mathrm{v})$ ethanol-water mixture and 0.1 $\mathrm{M} \mathrm{KCl}$ at various temperatures.

\begin{tabular}{|c|c|c|c|c|c|c|}
\hline \multirow[t]{3}{*}{$\mathbf{M}^{\mathbf{n}+}$} & \multicolumn{6}{|c|}{ Formation constant } \\
\hline & \multicolumn{2}{|c|}{$298.15 \mathrm{~K}$} & \multicolumn{2}{|c|}{$308.15 \mathrm{~K}$} & \multicolumn{2}{|c|}{ 318.15 K } \\
\hline & $\log K_{1}$ & $\underline{\log } K_{2}$ & $\log K_{1}$ & $\log K_{2}$ & $\log K_{1}$ & $\log K_{2}$ \\
\hline \multicolumn{7}{|c|}{ p-unsubstituted sulfonamide azo dye (I) } \\
\hline $\mathrm{H} \quad$ (I) & 7.9 & 9.75 & 7.80 & 9.63 & 7.70 & 9.74 \\
\hline $\mathrm{Mo}^{3+}$ & 11.74 & 9.60 & 11.51 & 9.45 & 11.31 & 9.32 \\
\hline $\mathrm{UO}_{2}^{2+}$ & 10.70 & 6.80 & 10.53 & 6.71 & 10.38 & 6.63 \\
\hline $\mathrm{VO}^{2+}$ & 8.00 & 6.40 & 7.88 & 6.32 & 7.78 & 6.25 \\
\hline $\mathrm{Co}^{2+}$ & 7.80 & 5.90 & 7.69 & 5.83 & 7.60 & 5.77 \\
\hline \multicolumn{7}{|c|}{$\mathrm{p}-\mathrm{N}\left(\mathrm{CH}_{3}\right)_{2}$ sulfonamide azo dye (II) } \\
\hline $\mathrm{p}-\mathrm{N}\left(\mathrm{CH}_{3}\right)_{2}$ & 7.40 & 9.98 & 7.30 & 9.85 & 7.20 & 9.71 \\
\hline $\mathrm{Mo}^{3+}$ & 11.35 & 9.23 & 11.14 & 9.08 & 10.96 & 8.95 \\
\hline $\mathrm{UO}_{2}^{2+}$ & 10.43 & 6.40 & 10.27 & 6.31 & 10.13 & 6.23 \\
\hline $\mathrm{VO}^{2+}$ & 7.70 & 5.90 & 7.58 & 5.81 & 7.49 & 5.74 \\
\hline $\mathrm{Co}^{2+}$ & 7.30 & 5.63 & 7.19 & 5.55 & 7.11 & 5.49 \\
\hline \multicolumn{7}{|c|}{$\mathrm{p}-\mathrm{NO}_{2}$ sulfonamide azo dye (III) } \\
\hline $\mathrm{p}-\mathrm{NO}_{2} \quad$ (III) & 7.15 & 9.95 & 7.02 & 9.81 & 6.90 & 9.67 \\
\hline $\mathrm{Mo}^{3+}$ & 11.07 & 8.87 & 10.88 & 8.73 & 10.72 & 8.61 \\
\hline $\mathrm{UO}_{2}{ }^{2+}$ & 10.17 & 5.80 & 10.02 & 5.72 & 9.89 & 5.65 \\
\hline $\mathrm{VO}^{2+}$ & 7.39 & 5.53 & 7.28 & 5.44 & 7.19 & 5.37 \\
\hline $\mathrm{Co}^{2+}$ & 6.83 & 5.40 & 6.74 & 5.33 & 6.66 & 5.27 \\
\hline
\end{tabular}

The following general remarks can be pointed out:

(a) the maximum value of $n$ was $\approx 2$ indicating the formation of $1: 1$ and 1:2 (metal : ligand) complexes only;

(b) the metal ion solution used in the present study was very dilute $\left(10^{-4}\right.$ $\mathrm{M})$, hence there was no possibility of formation of polynuclear complexes [10];

(c) the metal ion titration curves were displaced to the right-hand side of the ligand titration curves along the volume axis, indicating proton release upon complex formation of the metal ion with the ligand. The large decrease in $\mathrm{pH}$ for the metal titration curves relative to ligand titration curves points out to the formation of strong metal complexes [11];

(d) in most cases, the colour of the solution after complex formation was different from the colour of the ligand at the same $\mathrm{pH}$; 
(e) for the same ligand at constant temperature [12,13], the stability of the chelates increases in the order $\mathrm{Mo}^{3+}>\mathrm{VO}^{2+}>\mathrm{UO}_{2}{ }^{2+}>\mathrm{Co}^{2+}$.

Furthermore, with increasing electronegativity of the metal ions, the electronegativity difference between a metal ion and the donor atom of the ligand will decrease. Thus, the metal ligand bond would have more covalent character $[14,15]$, which in turn results in a greater stability of chelates compared to ligand ones. Moreover, the variation of the stability could be quantitatively accounted for by calculating the effective electric field strength $\mathrm{F}^{*}$ of the central metal ion $\left(F^{*}=Z^{*} / r^{2}\right)$, where $Z^{*}$ and $r$ are the effective charge and radius of the investigated cation, respectively. It is found that $\mathrm{F}^{*}$ is higher for $\mathrm{Mo}^{3+}$ than for $\mathrm{Co}^{2+}$, indicating its greater stability.

\section{Conductometric titration}

Stoichiometries of the complexes of ligands with $\mathrm{Mo}^{3+}, \mathrm{VO}^{2+}, \mathrm{UO}_{2}{ }^{2+}$ and $\mathrm{Co}^{2+}$ were obtained from the conductometric titration. These studies gave filtration curves characterized by two breaks of the positions denoting the formation of 1:1 and 1:2 (metal: ligand) complexes. Therefore, the reaction between the metal ions and ligand occurs via the formation of a covalent linkage with the oxygen of the $\mathrm{OH}$ group (aryl-moiety) and the nitrogen of the azo group. The increase in conductance values upon titrating metal ions by ligand is probably due to the libration of the hydrogen ions from the $\mathrm{OH}$ during the complex formation; the decrease of the conductance value occurs due to the increase of the volume of the metal ion upon chelate formation, which is accompained by a decrease in the value of diffusion coefficient of the particle and the lowering of the charge on the metal ion through covalent bond formation with ligand. The nature of the complexes is:

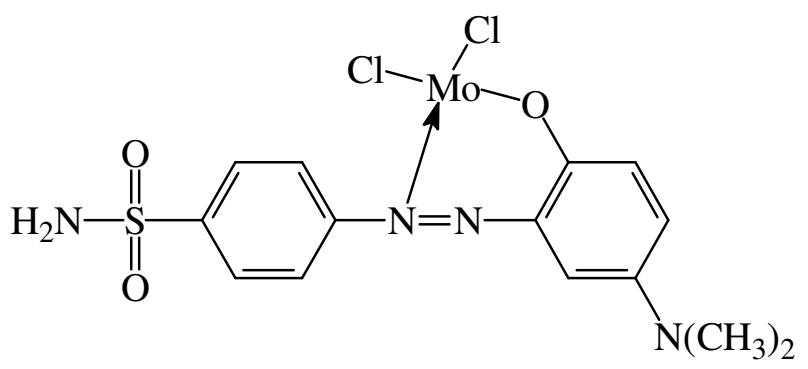

\section{Effect of temperature on the stability of the complexes and the thermodynamic parameters of complexation}

The stability constants of the complexes formed in 0.1 mole $\mathrm{KCl}$ and $20 \%$ (v/v) ethanol-water mixture were calculated at 298.15, 308.15 and $318.15 \mathrm{~K}$.

Ln $\mathrm{K}$ versus $1 / \mathrm{T}$ plots were utilized to evaluate the enthalpy change, $\Delta H$, and the entropy change, $\Delta \mathrm{S}$, for the complexation reaction according to the relation

$$
\mathrm{K}=(\Delta \mathrm{S} / \mathrm{R})-(\Delta \mathrm{H} / \mathrm{RT})
$$

The free energy change, $\Delta \mathrm{G}$, was calculated from the relation 


$$
\Delta \mathrm{G}=-\mathrm{RT} \operatorname{Ln} \mathrm{K} .
$$

The determined values are given in Table 2. Its inspection shows that the decrease in $\mathrm{K}$ values with increasing temperature suggests that the complex formation is exothermic and favourable at lower temperatures. This is verified from the negative values of $\Delta \mathrm{H}$. The negative values of $\Delta \mathrm{G}$ reveal that all complexes under investigation are formed spontaneously in solution. The entropy values, $\Delta \mathrm{S}$, for all complexes are positive, indicating that the disorder of the system increases much more rapidly than the increase in the order taking place in the chelation. This stems from the fact that the order of the arrangement of the solvent around the ligand and the metal ion is lost when the complex is formed.

Table 2. Thermodynamic functions for the complexation of sulfonamide azo-dyes with $\mathrm{Mo}^{3+}, \mathrm{UO}_{2}{ }^{2+}, \mathrm{VO}^{2+}$ and $\mathrm{Co}^{2+}$ at $308.15 \mathrm{~K}$.

\begin{tabular}{|c|c|c|c|c|c|c|}
\hline \multirow[t]{2}{*}{$\mathbf{M}^{\mathrm{n}+}$} & \multicolumn{2}{|c|}{$\begin{array}{c}\text { Free energy } \\
\left(\mathrm{KJ} \mathrm{mol}^{-1}\right)\end{array}$} & \multicolumn{2}{|c|}{$\begin{array}{c}\text { Enthalphy change } \\
\left(\mathrm{KJ} \mathrm{mol}^{-1}\right)\end{array}$} & \multicolumn{2}{|c|}{$\begin{array}{c}\text { Entropy change } \\
\left(\mathrm{KJ} \mathrm{mol}^{-1}\right)\end{array}$} \\
\hline & $-\Delta \mathbf{G}_{1}$ & $-\Delta \mathbf{G}_{2}$ & $-\Delta \mathbf{H}_{1}$ & $-\Delta \mathbf{H}_{2}$ & $-\Delta \mathbf{S}_{1}$ & $-\Delta \mathbf{S}_{2}$ \\
\hline \multicolumn{7}{|c|}{ p-unsubstituted sulfonamide azo dye (I) } \\
\hline $\mathrm{H} \quad$ (I) & 45.08 & 55.63 & 19.15 & 19.15 & 87.01 & 122.42 \\
\hline $\mathrm{Mo}^{3+}$ & 67.91 & 55.76 & 39.06 & 25.43 & 93.70 & 98.50 \\
\hline $\mathrm{UO}_{2}{ }^{2+}$ & 62.13 & 39.59 & 29.07 & 15.44 & 107.35 & 78.40 \\
\hline $\mathrm{VO}^{2+}$ & 46.49 & 37.29 & 19.99 & 13.63 & 86.09 & 76.80 \\
\hline $\mathrm{Co}^{2+}$ & 45.43 & 34.40 & 18.18 & 11.81 & 88.34 & 73.30 \\
\hline \multicolumn{7}{|c|}{ p-N($\left(\mathrm{CH}_{3}\right)_{2}$ sulfonamide azo dye (II) } \\
\hline $\mathrm{p}-\mathrm{N}\left(\mathrm{CH}_{3}\right)_{2}$ & 43.05 & 58.09 & 19.15 & 25.85 & 77.60 & 104.62 \\
\hline $\mathrm{Mo}^{3+}$ & 65.73 & 53.57 & 35.53 & 25.44 & 98.42 & 91.38 \\
\hline $\mathrm{UO}_{2}{ }^{2+}$ & 60.65 & 37.23 & 27.25 & 15.44 & 108.26 & 65.30 \\
\hline $\mathrm{VO}^{2+}$ & 44.78 & 34.28 & 19.09 & 14.54 & 83.32 & 64.10 \\
\hline $\mathrm{Co}^{2+}$ & 42.54 & 32.75 & 17.28 & 12.73 & 81.75 & 65.10 \\
\hline \multicolumn{7}{|c|}{$\mathrm{p}-\mathrm{NO}_{2}$ sulfonamide azo dye (III) } \\
\hline $\mathrm{p}-\mathrm{NO}_{2} \quad$ (III) & 41.40 & 57.85 & 23.93 & 24.89 & 56.72 & 106.89 \\
\hline $\mathrm{Mo}^{3+}$ & 64.19 & 51.33 & 31.80 & 23.62 & 105.24 & 90.57 \\
\hline $\mathrm{UO}_{2}{ }^{2+}$ & 60.65 & 33.75 & 25.44 & 13.63 & 109.37 & 65.30 \\
\hline $\mathrm{VO}^{2+}$ & 42.89 & 32.10 & 18.18 & 14.54 & 80.49 & 57.10 \\
\hline $\mathrm{Co}^{2+}$ & 39.71 & 31.44 & 15.44 & 11.81 & 78.97 & 63.80 \\
\hline
\end{tabular}

\section{Effect of substituent $R$ on the stability of the complexes}

For the same metal ion, a plot of $\log \mathrm{K}_{1}$ versus Hammett's constant $\left(\sigma_{\mathrm{R}}\right)$, reaches a linear correlation with a correlation coefficient approaching unity. The statistical results are summarized in Table 3 . The linear correlation and the negative values of the slopes reveal that the complexation of (II) and its derivatives is governed by the effect of the substituent $\mathrm{R}$ and is also favoured by increased electron densities on the coordination sites.

In an attempt to gain further information about the dependence of the stability of chelates on the basicity of the ligand, a plot of $\log \mathrm{K}_{1}$ for (I) chelates vs. the corresponding $\log \mathrm{K}_{1}$ values for (II) or (III) was constructed and analyzed statistically by linear regression. The following relations were obtained at 298,15 $\mathrm{K}$ with a correlation coefficient of ca. 1: 
$\log \mathrm{K}_{1}[(\mathrm{I})$ chelates $]=0.51+0.98 \log \mathrm{K}_{1}$ [(II) chelates]

$\log \mathrm{K}_{1}[(\mathrm{I})$ chelates $]=1.07+0.96 \log \mathrm{K}_{1}$ [(III) chelates]

The intercepts obtained (0.51 and 1.07$)$ correspond approximately to the basicity difference $\Delta \mathrm{pK}^{\mathrm{H}}$ for the amidic proton. These differences were found to be 0.50 and 0.89 , respectively [15]. This confirms that the basicity of the ligand is the main factor governing the stabilization of chelates of (II) and its substituted derivatives. In general, the complexation increases by increasing the electron density on the coordination site. The electron donor substituent p-N $\left(\mathrm{CH}_{3}\right)_{2}$ increases the charge density leading to higher stability, while the electronattracting one $\left(\mathrm{p}-\mathrm{NO}_{2}\right)$ decreases the charge density leading to less stable complexes.

Table 3. Statistical data for the $\mathrm{UO}_{2}{ }^{2+}$ complexes with (II) (see Experimental section) in different ionic strengths and solvents at various temperatures; correlation coefficients in all cases $\geq 0.98$.

\begin{tabular}{|c|c|c|c|c|c|c|c|c|c|}
\hline \multirow[t]{2}{*}{ Solvent } & \multirow[t]{2}{*}{$\%$} & \multirow{2}{*}{$\begin{array}{c}\mathrm{KCl} \\
\left(\mathrm{mol} \mathrm{L}^{-1}\right)\end{array}$} & \multirow{2}{*}{$\begin{array}{c}\text { Temp. } \\
\text { (K) }\end{array}$} & \multicolumn{3}{|c|}{$\log K_{1}$} & \multicolumn{3}{|c|}{$\log K_{2}$} \\
\hline & & & & Exp. $^{a}$ & Calc. & $-P^{0}$ & Exp. ${ }^{a}$ & Calc. ${ }^{b}$ & $-P^{0}$ \\
\hline Ethanol & 20 & 0.05 & 298.15 & 10.54 & 10.52 & 1.047 & 6.50 & 6.40 & 2.033 \\
\hline Ethanol & 20 & 0.10 & 298.12 & 10.43 & 10.42 & 1.069 & 6.40 & 6.31 & 2.004 \\
\hline Ethanol & 20 & 0.10 & 308.15 & 10.27 & 10.26 & 1.029 & 6.31 & 6.22 & 1.985 \\
\hline Ethanol & 20 & 0.15 & 318.15 & 10.13 & 10.12 & 0.988 & 6.23 & 6.14 & 1.965 \\
\hline Ethanol & 20 & 0.20 & 298.15 & 10.30 & 10.30 & 1.091 & 6.31 & 6.23 & 1.986 \\
\hline Ethanol & 20 & 0.10 & 298.15 & 10.20 & 10.21 & 1.092 & 6.22 & 6.13 & 1.965 \\
\hline Ethanol & 40 & 0.10 & 298.15 & 10.85 & 10.88 & 1.137 & 6.31 & 6.46 & 1.750 \\
\hline Ethanol & 50 & 0.10 & 298.15 & 10.13 & 11.15 & 1.115 & 6.60 & 6.56 & 1.751 \\
\hline Ethanol & 60 & 0.10 & 298.15 & 11.43 & 11.43 & 1.171 & 6.73 & 6.69 & 1.730 \\
\hline Ethanol & 70 & 0.10 & 298.15 & 11.85 & 11.85 & 1.273 & 6.92 & 6.90 & 1.774 \\
\hline Methanol & 50 & 0.10 & 298.15 & 10.83 & 10.80 & 1.107 & 6.41 & 6.39 & 1.612 \\
\hline Acetone & 50 & 0.10 & 298.15 & 11.68 & 11.72 & 1.461 & 6.81 & 6.83 & 2.205 \\
\hline Dioxane & 50 & 0.10 & 298.15 & 12.11 & 12.10 & 1.210 & 7.13 & 7.13 & 1.880 \\
\hline
\end{tabular}

${ }^{a}$ Potentiometrically; ${ }^{b}$ these values were obtained by linear regression of $\log \mathrm{K}$ versus Hammett's constant $\left(\sigma_{\mathrm{R}}\right){ }^{\mathrm{c}}$ slope of Hammett's equation $\left(\log \mathrm{K}_{\mathrm{R}}=\log \mathrm{K}_{\mathrm{H}}-p \sigma_{\mathrm{R}}\right)$.

Therefore, the order of decreasing stability constants for the ligands with the same metal ion at constant temperatures, ionic strength and the dielectric constant of the medium is to II > I > III.

\section{Effect of ionic strength and dielectric constant of the medium on the stability of the complexes}

The variation of $\log \mathrm{K}$ values with the ionic strength of the medium was investigated at $298.15 \mathrm{~K}$ and in $20 \%$ (v/v) ethanol-water. These values are listed in Table 4. An inspection shows that the stability constants of the complexes of these ligands with $\mathrm{UO}_{2}$ (II), as a typical example, decrease with increasing ionic strength of the medium, which is consistent with the Debye-Huckel equation [16], i.e., the tendency of the metal ion to form complexes decreases in the presence of other ions in the system where the metal ion is screened or competed by other ions. 
Table 4. Formation constants for $\mathrm{UO}_{2}{ }^{2+}$ complexes with substitued sulfonamide in different concentrations of $\mathrm{KCl}$ at $298.15 \mathrm{~K}$ and $20 \%$ (v/v) ethanol-water mixture. (I, II and III: see Experimental section).

\begin{tabular}{ccccccc}
\hline KCl & \multicolumn{2}{c}{ I } & \multicolumn{2}{c}{ II } & \multicolumn{2}{c}{ III } \\
\cline { 2 - 7 }$\left(\mathbf{m o l ~ L}^{-\mathbf{1}}\right)$ & $\mathbf{L o g} \mathbf{K}_{\mathbf{1}}$ & $\mathbf{L o g} \mathbf{K}_{\mathbf{2}}$ & $\log \mathbf{K}_{\mathbf{1}}$ & $\log \mathbf{K}_{\mathbf{2}}$ & $\log \mathbf{K}_{\mathbf{1}}$ & $\log \mathbf{K}_{\mathbf{2}}$ \\
\hline 0.20 & 10.50 & 6.62 & 10.20 & 6.22 & 9.96 & 5.64 \\
0.15 & 10.59 & 6.72 & 10.30 & 6.31 & 10.05 & 5.73 \\
0.10 & 10.70 & 6.80 & 10.43 & 6.40 & 10.17 & 5.80 \\
0.05 & 10.79 & 6.89 & 10.54 & 6.50 & 10.27 & 5.88 \\
$0.00^{*}$ & 11.09 & 7.16 & 10.90 & 6.79 & 10.59 & 6.12 \\
\hline
\end{tabular}

On the other hand, as indicated from Table 3, the order of increasing stability constant at various ethanol-water compositions is $20<40<50<60<70 \%$, which is the same trend of increasing basicity of the ligands [15] and decreasing dielectric constant of different aquo-organic solvents. The decrease in the dielectric constants with increasing the organic solvent content in the solvent increases the stability of complexes containing either $\mathrm{O}-\mathrm{M}$ or $\mathrm{O}-\mathrm{H}$ links $[17,18]$. This may be due to increased ion-ion interaction between the metal ion (or proton) and the anionic oxygen donor, surpassing the ion - dipole interaction between metal ion (or proton) and solved complexes. Moreover, for a particular composition $(50 \% \mathrm{v} / \mathrm{v})$ of the solvent-water mixture, these values decrease as follows: dioxane-water $>$ acetone-water $>$ ethanol-water $>$ methanol-water. This order is in accordance with decreasing 1/D and increasing basicity of the ligands [15].

\section{Solid complexes of chelation}

For IR spectra of complexes with $\mathrm{Mo}(\mathrm{III}), \mathrm{Vo}_{2}(\mathrm{I}), \mathrm{Uo}_{2}$ (II) and $\mathrm{Co}(\mathrm{II})$ chlorides, the bands due to $v_{\mathrm{C}-\mathrm{O}}$ are shifted to higher frequencies. This shift may be due to the increased covalence resulting from metal ion coordination. For bands at 450$600 \mathrm{~cm}^{-1}$ due to $v_{\mathrm{M}-\mathrm{O}}$, the presence of the two sharp intensity bands at 835 and $1690 \mathrm{~cm}^{-1}$ in the complexes indicates the presence of coordinated water molecules, compared with the IR spectral data of free ligand.

The interpretation of the IR spectrum of the metal chloride complexes shows an absorption at $1780 \mathrm{~cm}^{-1}$ corresponding to $\gamma$ - $\delta$-unsaturated lactones, which could be the source of the formation of chelation. The new broad weak or medium intensity band observed in the IR spectra of the chelates at $3240-3125 \mathrm{~cm}^{-1}$ is probably due to $\mathrm{V}_{\mathrm{OH}}$ of the water molecules. The strong band at $1660-1634 \mathrm{~cm}^{-1}$ in the spectra of the ligands assigned to $v_{\mathrm{C}-\mathrm{O}}$ and the $v_{\mathrm{C}-\mathrm{N}}$ at $1630-1605 \mathrm{~cm}^{-1}$ show a negative shift of $\sim 10 \mathrm{~cm}^{-1}$ on chelation, indicating that the carbonyl oxygen and the nirogen of the azomethine group are coordinated to the $\mathrm{M}^{2+}$ or $\mathrm{M}^{3+}$ ions. The non-ligand bands occurring in the $490-430 \mathrm{~cm}^{-1}$ and $350-400 \mathrm{~cm}^{-1}$ regions may be tentatively due to the M-O and M-N stretching modes, respectively. 


\section{Electronic absorption spectra}

The spectra of the solid complexes as nujol mulls show bands characteristic of the octahedral and tetrahedral forms, confirming the IR spectral data. The peaks of the chelates are observed for $\mathrm{Mo}(\mathrm{III}), \mathrm{Vo}_{2}$ (I) and $\mathrm{Co}(\mathrm{II})$ at the regions 19231$31546 \mathrm{~cm}^{-1}, 19231-31746 \mathrm{~cm}^{-1}$ and $19231-31746 \mathrm{~cm}^{-1}$, which correspond to the electronic transition, respectively:

$$
{ }^{6} \mathrm{~A}_{1 \mathrm{~g}} \rightarrow{ }^{4} \mathrm{E}_{\mathrm{g}}(\mathrm{D}) ;{ }^{6} \mathrm{~A}_{1 \mathrm{~g}} \rightarrow{ }^{4} \mathrm{E}_{\mathrm{g}}(\mathrm{D}) \text { and }{ }^{4} \mathrm{~A}_{2} \rightarrow{ }^{4} \mathrm{~T}_{1 \mathrm{~g}}(\mathrm{P})
$$

The spectra of the $\mathrm{Co}^{2+}$ and $\mathrm{Uo}_{2}{ }^{2+}$ complexes with the ligands under investigation exhibit bands at positions slightly different from those of free ligand in the regions 19231-31746 $\mathrm{cm}^{-1}$ and 19231-32258 $\mathrm{cm}^{-1}$, which correspond to the electronic transition ${ }^{3} \mathrm{~A}_{2 \mathrm{~g}} \rightarrow{ }^{3} \mathrm{~T}_{1 \mathrm{~g}}(\mathrm{P})$ and ${ }^{2} \mathrm{~T}_{2 \mathrm{~g}} \rightarrow{ }^{2} \mathrm{E}_{\mathrm{g}}$, respectively.

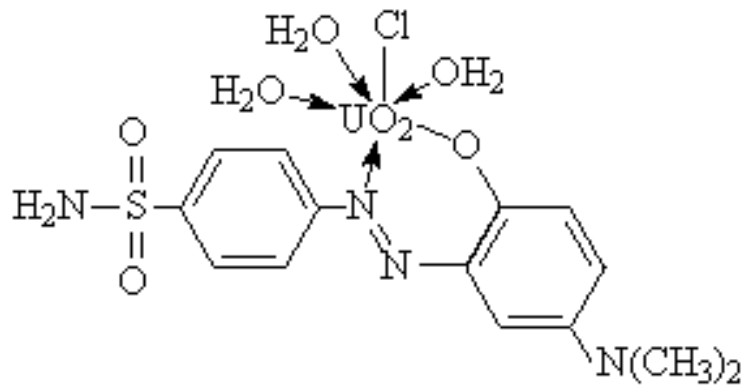

The spectra of the chelates were also recorded in DMF solution. The change in $v\left(\mathrm{~cm}^{-1}\right)$ values of the CT bands from those in the case of the nujol mull technique are consequent on the destruction of the crystalline state. Hence, the environment of the central metal ions differs in the solid state from that in solution. This is due to a distortion of the octahedral form tending to be tetrahedral or squareplanar of the same chelate, resulting from the dehydration of the complexes during the preparation of the mull.

In conclusion, the complexation of $\mathrm{p}-\mathrm{N}\left(\mathrm{CH}_{3}\right)_{2}$ sulfonamide azo-dyes substituted (II) with $\mathrm{Mo}(\mathrm{III}), \mathrm{UO}_{2}$ (II), $\mathrm{VO}$ (II) and $\mathrm{Co}(\mathrm{II})$ is spontaneous, exothermic and entropically favourable. The stability of these complexes increases with increasing electron-repelling property of the substituent and the organic content in the media, while the rise of temperature and the increase of ionic strength of the medium decrease their stabilities. Furthermore, the present ligands may be used as an analytical reagent for the determination of the metal ions under investigation. This is due to the high overall stability constants which reflect the stability of the formed complexes under prevailing experimental conditions. Furthermore, the molecular structure of the metal complexes were elucidated.

\section{References}

1. F.C. Brown, C.K. Brandsher, M. Tetenbaum, P .Wilder, J. Am. Chem. Soc. 78 (1956) 384.

2. A.A. El-Bindary, A.Z. El-Sonbati, E.H. El-Mossalamy and E.M. ElSanatawy, Spectrochimica Acta, Part A 57 (2001) 2359.

3. E.H. El-Mossalamy, E.M. Mabrouk, Bull. Electrochemistry 10 (1995) 484. 
4. K.M. Ibrahim, M.S. Abd El-Hammid, A.A. El-Bindary, M.M. Mostafa, Polyhedron 5(5) (1986) 1105.

5. E.H. El-Mossalamy, A.S. Amin, Monatshefte fur Chemie 128 (1997) 23.

6. K.M. Ibrahim, M.M. Beckheit, G.M. Abu El-Reash, Transition Met. Chem. 14 (1989) 454.

7. I. Shehatta, M.N.H. Moussa, M.A. Hafez, Thermochim. Acta 219 (1993) 121.

8. A.C. Fabretti, G.C. Franchini, G. Peyronel, Inorg. Chim. Acta 11 (1981) 52.

9. F.I.C. Rossotti, H.S. Rossotti, Acta Chem. Scand. 9 (1955) 1166.

10. G.R. Choppin, J.L. Brock, Inorg. Chim. Scand. 9 (1985) 1166.

11. A.M. Hammam, S.A. Ibrahim, J. Electrochem. Soc. India 29-4 (1980) 273.

12. M.T. El-Haty, F.A. Adam, R. Abdel-Hamid, E. Aboul-Kasim, Bull. Soc. Chem. France 1 (1987) 53.

13. Y.M. Temerk, A.Z. Abu Zuhri, I.M. Issa, M.M. Kamal, Indian J. Chem. 16 A (1978) 706.

14. L.G. Van Uitert, W.C. Fernelius, B.E. Douglas, J. Am. Chem. Soc. 75 (1993) 2736.

15. A.A. El-Bindary, I.S. Shehatta, E.M. Mabrouk, Monatshefte fur Chemie 125 (1994) 373.

16. J.T. Edsall, J. Wyman, (1958) Biophysical Chemsitry, Vol. 1 Academic Press, New York, p. 442.

17. D.B. Rorabacher, W.J. Mackeller, F.R. Shu, M. Bonavita, Analyst Chem. 43 (1971) 561.

18. B.S. Garg, M. Pal, R. Dixit, Thermochim. Acta 144 (1989) 13. 